\title{
After the Pandemic: Tech, Work, and the Tech Workforce
}

\author{
Aspen Russell* $\quad$ Eitan Frachtenberg ${ }^{\dagger}$
}

May 11, 2021

\begin{abstract}
Two major phenomena shaped the US's news for most of 2020: the Covid-19 pandemic and a new civil rights movement. The former required many employees, especially in tech, to switch to remote work. The latter has refocused attention of both employers and employees on questions of diversity, equity, and inclusion (DEI) in the workplace. In this article, we examine the intersection of these events and their effects on the tech work landscape. Starting from the assumption that remote work will continue to some extent when the pandemic is over, we ask: how will this transition affect different populations from a DEI perspective? We make predictions on technology and the workforce based on current trends and data for six marginalized populations. Keeping in mind that many people share characteristics with these groups, we also attempt to generalize our predictions to the entire tech workforce, and speculate on their benefits, risks, and impact.
\end{abstract}

\section{WORKING DRAFT COPY ONLY}

Please cite final version:

Aspen Russel and Eitan Frachtenberg. Worlds Apart: Technology, Remote Work, and Equity. In IEEE Computer 54(7), July 2021. DOI: 10.1109/MC.2021.3074121

\footnotetext{
*Department of Computer and Information Science, Cornell University, Ithaca NY

${ }^{\dagger}$ Department of Computer Science, Reed College, Portland OR
} 


\section{Introduction}

Predicting the future of technology and its societal impacts is challenging even in unremarkable years [1]. With the additional uncertainty introduced by a global pandemic, past predictions grow quickly irrelevant while new predictions are even more challenging. Nevertheless, two recent phenomena that have captured the global attention throughout 2020 do not show signs of abating any time soon. Both the Covid-19 pandemic and a new civil rights movement are deeply interwoven with technology, and the continued focus on these phenomena into 2021 allows some extrapolation on their evolving relationship with technology.

In the hands of humans, technology reveals the interdependence it has with other sectors of society. For example, in late March 2020, facing catastrophic shortages of ventilators, engineers created a digital design of a component used in ventilator development. This design could be easily distributed and reproduced, thus helping the immediate demand for ventilators and saving lives. However, this work was met with patent infringement threats shutting down a potentially life-saving act [2]. When considering technology speculations, the line is not always obvious between technology and society. It can be direct, or indirect, and proactive or reactive.

The Covid-19 pandemic looks starkly different than previous ones because of technology. On the one hand, technological advances such as aviation accelerated the spread of the pandemic [3]. On the other hand, technology is also accelerating development in treatments and vaccines, as well as inventions that curb the devastation from this deadly virus $[4,5]$. Technology has also enabledand the pandemic has required - a near instantaneous transformation of many industries from the traditional centralized workplace to the distributed, remote model, the focus of this article.

As of May 2020, about 35\% of the US workforce was remote, with whitecollar, higher-educated positions being the first to transition in large numbers [6-8]. Increasingly since then, we see a rise in remote work for other workers as well [9]. A recent survey found that not only is remote work surging, but that it is also improving employees' productivity, work-life integration, and accessibility [10]. Technology has historically played a huge accessibility role in communication and connection, and many workers already use virtual private networks, telepresence technologies, virtual meetings, cloud technology, work collaboration software, and more [11]. It was not always clear whether remote work at scale could succeed. The sudden transition forced by the pandemic has demonstrated that it not only works well for many employers, but that it can actually increase general employee satisfaction and participation, improving diversity and inclusivity $[10,12]$. With this new experience, there is a convincing case to keep remote work at some capacity even after the pandemic has subsided [13]. Our main prediction and premise for this article is that a significant part of the post-pandemic workforce in tech will continue in a remote or hybrid work model (see Table 1). 
Table 1: Current and post-pandemic work-from-home (WFH) policies for ten of Forbes' 2019 most-valuable tech companies (data as of November 2020). Number of employees is the latest estimate from Web sources.

\begin{tabular}{l|r|l}
\hline Company & Employees & Remote-work policy \\
\hline \hline Alphabet & 200,000 & $\begin{array}{l}\text { WFH through July 2021 [14], considering hy- } \\
\text { brid model afterwards [15] }\end{array}$ \\
\hline Amazon & $1,000,000$ & $\begin{array}{l}\text { White-collar employees WFH through Jan- } \\
\text { uary 2021 [16] }\end{array}$ \\
\hline Apple & 140,000 & $\begin{array}{l}\text { WFH through 2020 [17], unspecified perma- } \\
\text { nent changes expected [18] }\end{array}$ \\
\hline Cisco & 75,900 & $\begin{array}{l}\text { Cisco sells remote-work tech and expects a hy- } \\
\text { brid model post-pandemic [19] }\end{array}$ \\
\hline Facebook & 52,500 & $\begin{array}{l}\text { Up to 50\% of employees fully remote within } \\
5-10 \text { years [20] }\end{array}$ \\
\hline IBM & 350,000 & $\begin{array}{l}\text { WFH through the pandemic, planning to re- } \\
\text { turn to office post-pandemic [21] }\end{array}$ \\
\hline Intel & 110,800 & $\begin{array}{l}\text { WFH through June 2021, expecting gradual } \\
\text { return to office post-pandemic [22] }\end{array}$ \\
\hline Microsoft & 156,500 & $\begin{array}{l}\text { Hybrid and remote model, with part-time } \\
\text { WFH standard [23] }\end{array}$ \\
\hline Netflix & 8,600 & $\begin{array}{l}\text { No WFH expected six months after a Covid- } \\
19 \text { vaccine [24] }\end{array}$ \\
\hline Oracle & 135,000 & $\begin{array}{l}\text { Planning return to offices with exceptions } \\
\text { based on personal circumstances [25] }\end{array}$ \\
\hline
\end{tabular}


Even if you are unable to work from home, it is likely many of your services and interactions will now take place over video calls or be reliant on some form of technology. Depending on other systemic issues, your access and interaction with these technologies will vary greatly, if you are able to access them at all. For these reasons, technology speculation is not a neutral or apolitical act. It is critical to know that the relationship between need identification, innovation, and user experience underlies impact. Many of the issues concerning diversity, equity, and inclusion (DEI) will be missed by tech innovators.

For this reason, our speculations should serve multiple purposes. One of them is to outline a few communities of people that will be affected by the pandemic in drastic ways. We attempt to bring context to the varied experiences and issues that inform our speculations and hopefully act as a call to action to tech workers, who have the greatest opportunity to craft needed change. In the next section we examine six specific populations as case studies: people in a care role; women; transgender and nonbinary people; black, indigenous, and people of color; immigrants and nonnative English speakers (NNES); and people with disabilities.

In each of the six subsections we offer a brief background on specific circumstances of each population. We then extrapolate predictions on technology or the workforce on the DEI aspects of remote work for this population. We phrase our predictions optimistically, but remind the readers that technology is a tool and humans will ultimately decide its trajectory. In Sec. 3, we generalize our DEI predictions to the entire tech workforce, and in some cases for all remote workers. Finally, in Sec. 4 we summarize and visualize our complete set of predictions, speculate on their likelihood and impact, and discuss the factors that could lead to their realization.

\section{Predictions by Population}

\subsection{People in a Care Role}

For the remote workforce, care labor may be the most visible issue. At first glance, the privilege of working from home is removing, or reducing, the distance gap between yourself and the people whom you provide care to, but new challenges also arise.

Care giving has always been a contentious issue that persists despite gains in household labor equity [26-31]. Mothers in heterosexual relationships are still performing disproportionate care labor, which is affecting their families and careers [28, 30,32-35]. During the pandemic, educational support has become a major source of tension in households. A recent survey by the Society of Women Engineers indicated that while women often shared childcare responsibilities with their partners, educational support fell almost exclusively on them [36]. This disparity is noteworthy, as education is a new skill to learn for many parents [13]. Those with children are managing both the logistics and anxiety of sending their children back to school during a pandemic, closures, 
homeschooling, and a host of chores like cooking and cleaning that predated the pandemic.

These circumstances grow more complex if you must leave your house to perform care duties, which is common for elder care. Older people are more susceptible to illness, and this is certainly true for Covid-19 [37]. Many caregivers are going to weigh the consequences of visiting an elder if it means placing them at higher risk, potentially leading to reduced contact and services. In all cases, the role of emotional labor increased to a higher priority. Explaining changing circumstances and helping loved ones process the precarity of a pandemic is an added stressor on everyone in a care role, but typically falls on women $[33,38,39]$.

These issues represent systemic problems that were ever-present prior to the pandemic, but have now grown more visible. The pandemic caused widespread visibility of these issues when it placed more pressure on the seams that were struggling to hold it together in the first place. Technology will not solve these issues alone; it did not cause these issues on its own. However, technology has a unique role to play in addressing problems both new and old as its workforce occupies the unique position of being subject to remote work and innovating much of the technology needed to successfully work.

Based on these observations, we make the following predictions:

- At-home work and care support from employers. Major tech companies that are located in high cost-of-living regions may offset office space costs by supporting at-home employees with elder and other care responsibilities through reimbursement, home adjustments, and schedule flexibility [22]. This resource redistribution should allow employees with care responsibilities greater work-life integration.

- Advances in remote education technologies. To support at-home education, video platforms will need to address kinetic forms of engagement for children. Allowing students to move and speak to engage with material can help address issues of distractability or apathy. Broadening the tool-set for engagement can include: the use of mobile devices for speech-to-text note-taking, using augmented reality to visualize school work, and digital assistants to ask questions. Future teaching technology could also offer teachers a more complete picture of what and how students are doing, and more natural tools to incorporate props and teaching aids.

- Advances in communication technologies for the elderly. Elder care is becoming more dependent on digital means of communicating. Mastering new technologies is particularly difficult for those with low tech exposure or with disabilities. Technology needs to provide seamless and secure access, with improvements to accessibility controls, to communication applications for loved ones and medical professionals. 


\subsection{Women}

Women are likely the largest demographic to experience adverse work effects because of Covid-19. More women lost their jobs than men, especially when we account for women with multiple, intersecting marginalized identities $[13,40]$. This job loss disparity also has tangible impacts on our ability to innovate or contribute to research during the pandemic, even tackling the virus itself [41]. ${ }^{1}$ Even when working from home, much of the care workloads falls on women's shoulders. These effects could widen the gender gap in the workplace [42], and could especially set back the tech industry, which had already been struggling to narrow this gap [43].

This disparity also has tangible impacts on our ability to innovate or contribute to research during Covid-19, some of which is on solutions concerning the virus itself [44]. For example, the proportion of women first authors in medRxiv, a popular preprint repository for medical research, dropped from $38 \%$ in July 2019 to $20 \%$ in April 2020 [45]. Women's posts on the arXiv and bioRxiv repositories show a plateau, whereas men's rates have actually risen during the same time period [45].

On the flip side, there is also renewed interest in improvement. As nearly every tech worker is currently required to work from home, some men are partaking more in the home-based education of their children and other household tasks $[13,46,47]$. More men are discovering the value and effort of unpaid domestic work, leading to marked short-term improvements in domestic work equity [48], possibly with long-lasting effects after the pandemic [42]. Currently, many employers are still allowing men to get more work done, implicitly expecting women to take a disproportionate amount of the burdens in service work and at home. But employers - who are also WFH and witnessing this inequity firsthand - may also shift to more egalitarian expectations and policies [42]. Their explicit and implicit expectations should evolve to allow everyone the same access to leave, flexible work arrangement, retention, and of course, pay and promotion, with the understanding that the recent increase in awareness needs to translate into equitable policy.

Another important aspect when considering gender at work is that of sexual harassment and discrimination. Although remote work reduces the risk of physical sexual harassment, it can still take place in virtual spaces [49]. Similarly, the pay gap, preferential treatment, bias in evaluation, and uneven expectations did not go away with the at-home office. Like other gender minorities (described in the next section), often being seen only as a gendered name in textual communication can decrease empathy and increase bias further. Even the universal phenomenon of discounting women in meetings unfortunately survives the format change from meeting to video. For example, one in five women has recently felt ignored and overlooked by coworkers during video calls [47].

Some of the additional challenges faced when combating harassment and discrimination in a remote work environment are the lack of formality and ci-

\footnotetext{
${ }^{1} \mathrm{An}$ interactive, up-to-date visualization of the gender gap in preprint submissions can be found at https://bit.ly/3deSH4q.
} 
vility in online environments, in-person witnesses, and monitoring of employee conduct. Both employers and employees need to adapt to this "new normal." Sexual harassment training, management, and prevention tools must therefore be aligned with the times we are living in.

Based on these observations, we make the following predictions:

- Improved gender balance in domestic work. In the short term, women will continue to bear more of the burdens at home, their careers are more likely to be adversely affected, and the sticky gender gap in technology could be widening. But as the tech industry transitions to permanent flexible work models and as participation of men in domestic work increases, they hold the potential to weaken established gender norms, leading to improved equity.

- Improved gender balance in tech companies. With the long-term improvements to the gender balance at home, employers may adjust their work expectations accordingly, and accommodate all genders more equally. It is plausible that improvements to gender diversity and equality in the workplace would follow as well, leading to a reduction of the gender gap in the tech workforce.

- Policies and tech to address harassment. Workplaces will develop new policies to govern appropriate online behavior of employees. These policies may be augmented by technological aids, which in turn raises issues of employee security, agency, and privacy. However, the software could document and record evidence locally on the employee computer (to be used and viewed at the discretion of the employee), automate the filing of harassment claims, and protect anonymity.

\subsection{Transgender and Nonbinary People}

Little is known about how exactly the pandemic affects transgender and nonbinary people specifically, because many institutions do not collect holistic demographic data [50]. However, there are several proxies we can use to identify how trans and nonbinary folks may be faring.

In the last few years influential legal decisions were made concerning the rights of transgender people. A Supreme Court ruling extended coverage of the Civil Rights Act of 1964 to cover sexual orientation and gender identity. However, the Trump administration banned transgender people from serving in the military and made it legal for private healthcare providers to discriminate against transgender patients [51-53]. For transgender people of color, these rulings snowball as they are disproportionately experiencing higher rates of H.I.V. and homelessness [54]. All of which can directly influence workplace policy and norms.

Shifting to remote work, at first glance it appears that transgender and nonbinary people will have more autonomy over their day-to-day. For instance, the agency of video cameras, space and time to present yourself comfortably, 
and access to a private restroom can all contribute to better work conditions, not limited to gender minorities. We also know that the act of transitioning, or having someone in your workplace transition, does not always improve the norms and culture of the office [55]. Specifically for transgender people, coworkers can reinforce gender norms [56]. For female-to-male (FTM) trans people, this can mean receiving more authority, higher pay, and more respect, with white FTM trans people faring better than of color [56]. Some researchers suggest that without a traditional gender to hold onto, nonbinary people in the workplace are looked on even less favorably [57]. All of these examples point to solutions regarding the workplace more broadly, rather than finding a means to an end for someone's identity.

Based on these observations, we make the following predictions:

- Bias-sensitive machine learning. Machine learning has been criticized when trained with inadequate and biased data [58]. Many facial recognition algorithms cannot adequately recognize race or gender, let alone people who fall outside of the traditional gender binary [59]. Such automation must evolve to bring awareness of issues and diagnose the forms of bias we are seeing [60]. This will change the role we see computational work taking on, instead of propagating biased artifacts of software developers, we can work with automation to tackle these critical problems.

- Bias-detecting machine learning. Similar to gender bias based on names, transgender and nonbinary people will experience these and a host of unique issues for workplaces unaccustomed to queer people [61]. Technologies such as browser- and application-plugins can be built to provide communication nudges and moments of reflection before sending, but also to offer education and information for revision concerning language use.

- Language accessibility tech. Technology that allows for quick, accessible understanding of office policies, state and federal laws, and courses of action to rectify transgressions will need to develop rapidly. Instead of placing the onus on marginalized people to become law or healthcare experts, technology has the opportunity to offer education and the agency to make an informed decision.

\subsection{Black, Indigenous, and People of Color (BIPoC)}

Police brutality gave rise to massive BLM protests and a renewed civil-rights movement amidst a global pandemic. These circumstances provided unprecedented global awareness of many systemic failures. They are a sobering reminder of the relationship between the effects of longstanding inequity and sharp, immediate effects of crisis.

National health data on Covid-19 and race is not comprehensive. Few states are releasing statistics, but from those that do, we can see a stark trend: BIPoC communities are being disproportionately affected by the pandemic [62]. Fac-

tors include the structural issues predating the virus such as: higher rates of 
chronic conditions; higher population density; reduced access to medical care; and reliance on public transportation [62]. BIPoC people are also more likely to be on the front lines of fighting the pandemic as essential workers [62]. The deadly combination of inadequate medical care and higher risks of front-line work makes every precautionary step in risk mitigation that much more important. Washing your hands, wearing a mask, and social distancing are three prominent recommendations to reduce risk of contracting Covid-19. However, the first step is incredibly difficult to accomplish if you do not have access to running water. Indigenous households are 19 times more likely than white homes to lack plumbing [63]. Black and Latinx ${ }^{2}$ homes are twice as likely as white homes to lack running water [63]. While working from home can alleviate many issues, how you travel when you must leave, and the home that you will be working in, must be factored into the equation.

$\mathrm{BIPoC}$ communities were already feeling disproportionate effects from inequitable systems. The pandemic has acted as catalyst to these issues resulting in BIPoC harm and death, who are also overrepresented on the front lines. Even from the small sample of statistics above, it is clear how important technology and communication is to bring visibility to inequity, to communicate vital medical information, and to address longstanding systemic issues. All of which will be essential components moving forward to adequately move the needle on the needs of BIPoC communities

Based on these observations, we make the following predictions:

- Democratized at-home safety tech. With more people forced to use their homes for both work and life, technology will evolve to democratize health and safety testing, such as at-home, affordable testing for illness (ranging from the flu to Covid-19), water, air, and more.

- Tech company partnerships with marginalized communities. Innovation depends on strong, equitable partnerships with the communities it affects. More accessible or open-source software can lower the technical barrier for communities without tech infrastructure. Also, developers can apply these lessons by addressing issues of internet access, language, and culturally specific features and needs. One successful example of this is SIKU, the indigenous knowledge social network, created by Inuit people to communicate which plots of sea ice are safe to walk or snowmobile across due to climate change

- Expanded services via video platform. Building off the transition to telehealth, more services can soon be conducted seamlessly through video and voice platforms [64]. This should bring down the cost and accessibility of these services, essentially creating online, visual marketplaces.

\footnotetext{
${ }^{2}$ Latinx is the gender-neutral version of Latina/o.
} 


\subsection{Immigrants and Nonnative English Speakers}

The pandemic slowed down international travel and forced many immigrant workers and students to switch to a remote-only model from their home countries. These people may face additional challenges to remote work compared to domestic workers, such as poor bandwidth or infrastructure, inconvenient meeting times in their time zones, and overall worse communication with their domestic peers. These challenges pose barriers to effective interviewing and hiring, and could lead to difficulties in obtaining or changing employment for nondomestic candidates. Consequently, more immigrants than native-born employees lost their jobs, with only about a third of these jobs not "remoteable" [65].

Even when employment is secured, nondomestic and nonnative workers face additional challenges. Compared to face-to-face meetings, remote communication is slower and more challenging, especially for people in a different time zone or with language or accent barriers. Poor quality video or audio and inconvenient meeting times can significantly slow down collaboration. On the other hand, remote communication tools can also be beneficial, if used effectively. For example, video recording [66] and live captions (or even translation) can help nonnative speakers understand better, and text-based communication can help make them better understood. Video recording can also help catch up with meetings missed due to timezone mismatch.

Based on these observations, we make the following predictions:

- Tools to bridge language- and time-zone gaps. The development of tools that enable telecommunication across continents and languages will accelerate with novel and improved features because of the acute demand. Recent developments in artificial intelligence could augment these tools by automating tasks such as translation, editing, and scheduling. Special attention should be paid to cultural and regional language differences and the effects of daylight savings and time zones.

- Global workforce as a norm. Even long before the pandemic, technology workers were growing more geographically diverse [67]. The constraints on travel placed by the pandemic - compounded by recent policy changes that further restricted tech immigration - are accelerating this process. The rise of massive open online courses, available from anywhere in the world, further grows the pool of nondomestic candidates. We predict that with improvements in telecommunication tools, this trend to grow to the point where a collaborative, global workforce becomes the norm in tech companies. Even onboarding activities such as recruiting, interviewing, hiring, and training may transition to a fully-remote model, which will increase the available talent pool to employees who cannot or will not immigrate for work.

- Advanced remote collaboration, training, and hiring. Organizations will need to learn new workflows and adopt new tools to boost the effectiveness of collaboration across borders, time zones, available band- 
width, and language skills. We predict a growing adoption and development of text-based collaboration tools like Slack or Asana, just as text-based communication has largely replaced voice-based communication for younger generations. Collaboration tools can also extend beyond text to digital twins or augmented and virtual reality workspaces. Such workspaces can emulate aspects of the in-office interactions, such as the proximity-based video chat approach of GatherTown (http:// gather.town). Another important aspect ripe for development is that of training and teaching. The video-conference classroom is currently too limited, compared to physical classrooms, with many important two-way interactions lost.

\subsection{People with Disabilities}

Defining disability can be complicated [68]. Depending on the context, it could refer to the legal definition, workplace policy, or simply the ability to perform a certain task or job. There is also little consensus among the disability community about terminology, such as using "people with disabilities" or "disabled persons." Conditions and impact span a broad spectrum, so it makes sense to consider first how the environment itself has an effect on ability.

For example, a programmer in a wheelchair may find a particular work environment physically challenging to navigate, but at home their productivity may be indistinguishable from any other programmer's. Similarly, a person with attention-deficit disorder may not even think of themselves as having a disability, until they join a company employing an open-space office, rich with distractions and sensory stimuli [69]. On the flip side, some workers may find the remote workplace too isolating and distressing compared to the shared office $[11,70]$. Others may find that "Zoom fatigue" or home-based distractions actually disadvantage them more than their colleagues, and may also prefer the traditional office model. All of which point to the environment itself as a mechanism to disable people, an important consideration for employers.

When the commute or conventional work environment present barriers to some employees, remote work unlocks the potential to better accommodate their needs and abilities [12]. An individualized workspace, equipment, or location can actually improve workers' productivity [10,71-73]. The investment in productive and healthy home offices, however, may fall well below the average workers' compensation claim [74]. With the sudden, unplanned transition to remote work, the typical expectation of companies is that employees bear this cost and provide their own workspace needs. But as we transition towards remote-first employment and hiring, it makes sense to discuss the employer's responsibility to improve access to productive, fulfilling work.

Based on these observations, we make the following predictions:

- Better work-life integration for workers with disabilities. People with disabilities working from home can especially benefit from a tailored environment, better planning and execution of tasks, meaningful breaks, 
increased comfort, and even a lower likelihood to experience microaggressions from coworkers $[75,76]$. Technology cannot address the underlying systemic issue of ableism, but it can create a more level playing field for all employees. We therefore predict that job satisfaction and performance for this group in particular would increase.

- Hybrid model for inclusion of people with disabilities. A conventional office space does not support all employees' needs and abilities equally, but neither does a fully remote model. We predict that many companies will adopt a hybrid or flexible model. To succeed in the integration of people of different abilities into this model, companies need to proactively and fully support these employees $[77,78]$. We also hope this will help to destigmatize disability.

- Normalization of accessibility in the tech workforce. The forced large-scale experiment in telecommuting should prove eye-opening and game-changing to both employers and employees. Many employers may witness the consequent improvements in diversity, and encode accessibility support for remote workers in their permanent policies. Many employees may also feel encouraged to request accommodations and support, in a way that permanently reinforces the advantages of remote and hybrid work models. Normalizing the full participation of currently employed people with disabilities will hopefully lead to intentional recruitment and retention of new employees with disabilities as well.

\section{Predictions for the Workforce as a Whole}

By outlining six communities whose needs often go unaddressed, we hope to bring awareness to new problems and pique the creative energy of technologists to solve them. Not every issue will fit perfectly in a category in practice, but their complexity and existence should instigate reflection. To reiterate our overarching prediction, we believe that tech will widely adopt work-from-home and hybrid models post-pandemic. The tech workforce will become a focal point of the success of this model from a DEI perspective. Companies will differ in policies. Employees, with their newfound remote experience, will make career decisions based of these policies. Consequently, worker mobility and workplace accessibility with shift as well.

With the normalization of WFH and hybrid workplaces, employee opportunities will broaden beyond where they live. Of the 60 million daily hours that Americans are no longer wasting on commuting, one third is added back to work and two thirds to other activities [79]. This extra time can both increase work productivity and free up time to address care needs, potentially upending gender roles [80]. The decentralization of talented and educated workforce could also have an equalizing economic impact both on the lived-in communities and on tech hubs, if supported by appropriate regulation [81]. 
Combining diverse geography with employer-provided at-home office support can create spaces that allow a greater proportion of the tech workforce to engage meaningfully in work. Employers could see savings from lower facility costs and reduced worker's compensation liabilities. We predict that successful hybrid companies will pass some of these cost savings to employees' workspaces. Some employers (e.g., Intel) already offer reimbursement to WFH workers for office supplies [22].

Increasing mobility and accessibility will allow the talent pool to grow. This transition and normalization of WFH and hybrid models could lead to gains in DEI. Minimizing geography and accessibility issues will allow for far more people to participate in tech. At-home offices, ergonomic equipment, and accessible software will level the playing field for employees. Forward-thinking policies that value and promote a variety of experience and thought will help with recruitment and retention.

That said, DEI is not merely a question of economics. Many practical questions remain on how to integrate and include everyone under the shared company vision and values. Open questions remain: How can you make sure that everyone is equally included in meetings, whether local, remote, or in a different time zone altogether? How do you shift to evaluate employees' contribution without actually seeing them at work? How do you instill a shared sense of mission in team spirit when the human experience of social interactions is predominantly local?

These are not simple challenges, but we believe that addressing them successfully can drive adjustments to company culture and policies that benefit everyone, especially for marginalized populations. The pressures to drive these changes will come from the employees themselves, from society's renewed commitment to social justice, from regulatory policies, and ultimately, from the economic self-interest of companies dependent on a talented and diverse workforce.

\section{Conclusion and Call to Action}

Many of the people who work on technology do so because they believe that it can better the human condition. Fig. 1 recaps all of our predictions and shows that we too believe that these innovations could generally be more beneficial than harmful. It also shows a positive association between the two. In other words, we believe that predictions with higher potential impact are generally also more at risk of abuse.

Our premise was that the widescale adoption of remote work in the technology sector will hold indefinitely. The scale of adoption is significant, affecting every country directly or indirectly. Most of our predictions assume a perspective of regions with a high density of technology developers and infection rates, both of which are true in North America and Europe. Nevertheless, many of the predictions proposed will also have broader effects. Predictions that use technology to address social issues, such as work-life integration, normalizing 
disability, identity-based harassment, and worker mobility, have high mapping potential to other countries. In general, most predictions are highly applicable outside the scope of the US, though the level of urgency and impact will vary greatly.

The key to generating and understanding these predictions lies with identifying the needs of those most harmed by the pandemic. As is plain from glimpsing into the experiences of marginalized people, the brunt of day-to-day inequity in emotional and care labor, access to basic resources, safety, and privacy are placed on these communities. The global pandemic has only amplified these effects for everyone. We have therefore an unprecedented opportunity to reevaluate our priorities given the background and speculations outlined in this article. The peremptory mass transition to remote work has shown the enormous potential for further development of person-centric workspaces. However, social transformations at this scale do not simply emerge with awareness and time. Tech companies, who have seen some of the greatest profits during the pandemic, will need both external and internal incentives to move in a more equitable direction.

The long-term success of the hybrid work model depends on multiple factors coming together. For this work model to exist in an equitable and inclusive way, employers need to fully commit to supporting all employees, in policies, health, trust, equipment, and technologies. There must also be an intentional and critical awareness of how technology influences and affects other sectors, such as law and public policy. We have witnessed the effect employees have had on the direction and ethics of the company they work for, such as in Google employees' fervent protest of its ethical practices in 2018.

When people are able to take care of themselves and center their work on the most pressing needs, our entire society is elevated. Our speculations live in the timeline that chooses to use empathy to inform innovation. Innovation of technology, policy, and practice. We now have an immense opportunity to make this reality come to fruition. 
Figure 1: Summary of all predictions based on the authors' subjective value judgemnt. The $\mathrm{X}$-axis represents the potential positive impact of the speculation. The Y-axis represents the potential of companies and policymakers to take advantage of people or cause harm. A data point's size represents how confident we are that the speculation will be realized, and its shape represents the primary driving force to effect each change. Color represents the affected population and section of the article that explains the prediction.

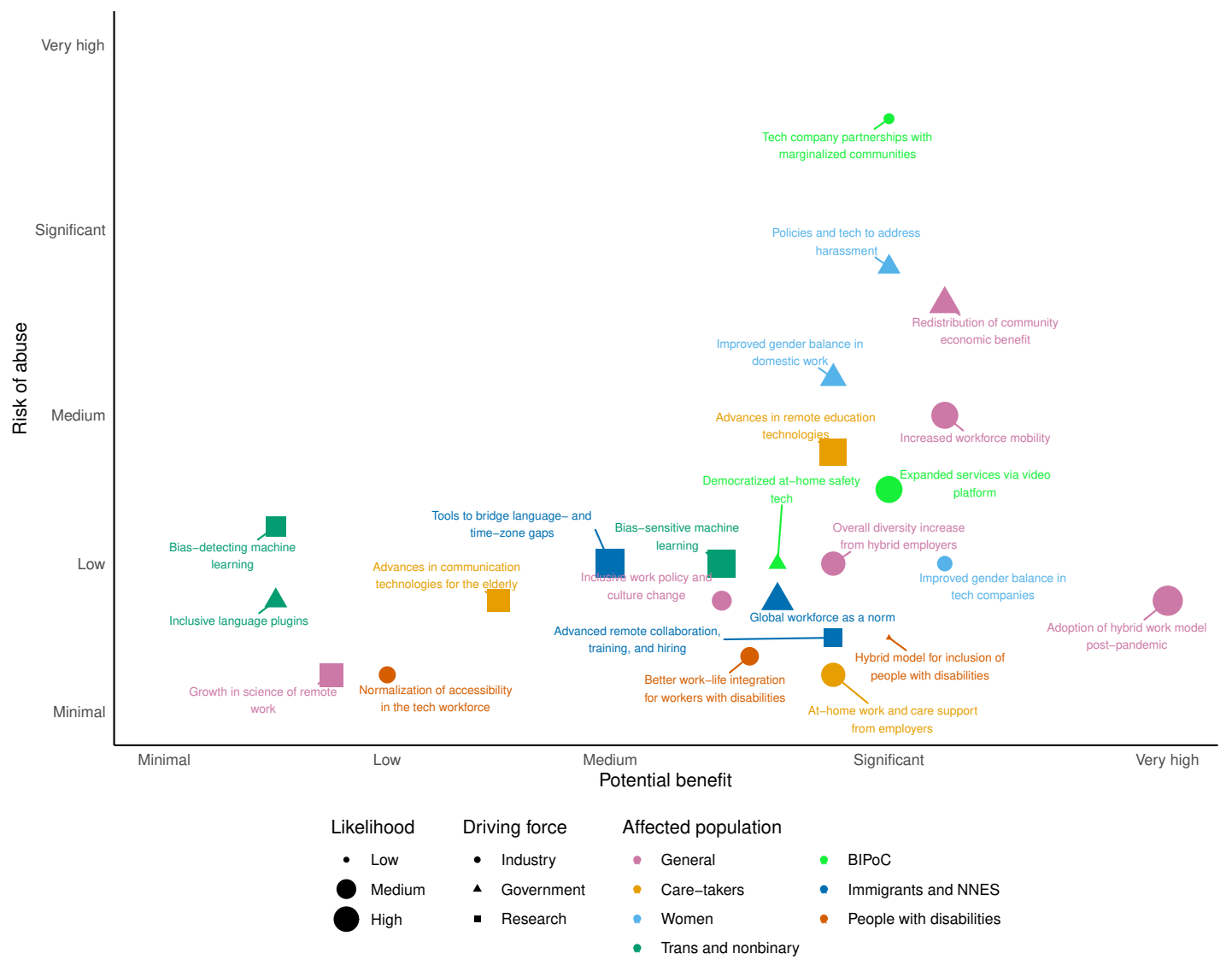




\section{References}

[1] P. Faraboschi, E. Frachtenberg, P. Laplante, K. Mansfield, and D. Milojicic, "Technology Predictions: Art, Science, and Fashion," IEEE Computer, vol. 52, Dec. 2019.

[2] J. Contreras, "Patents and Coronavirus - the right to repair," Apr. 2020.

[3] N. C. Khanh, P. Q. Thai, H.-L. Quach, N. Thi, P. C. Dinh, T. N. Duong, L. T. Q. Mai, N. D. Nghia, T. A. Tu, N. Quang, et al., "Transmission of severe acute respiratory syndrome coronavirus 2 during long flight.," Emerging infectious diseases, vol. 26, Nov. 2020.

[4] N. Bloom, S. J. Davis, and Y. Zhestkova, "Covid-19 shifted patent applications toward technologies that support working from home," University of Chicago, Becker Friedman Institute for Economics Working Paper, no. 2020-133, 2020.

[5] J. Budd, B. S. Miller, E. M. Manning, V. Lampos, M. Zhuang, M. Edelstein, G. Rees, V. C. Emery, M. M. Stevens, N. Keegan, et al., "Digital technologies in the public-health response to covid-19," Nature medicine, pp. 1-10, Aug. 2020.

[6] A. Adams-Prassl, T. Boneva, M. Golin, and C. Rauh, "Work tasks that can be done from home: Evidence on variation within \& across occupations and industries," 2020.

[7] A. Bick, A. Blandin, and K. Mertens, "Work from home after the COVID19 outbreak," 2020.

[8] R. Espinoza and L. Reznikova, "Who can log in? the importance of skills for the feasibility of teleworking arrangements across oecd countries," 2020.

[9] C. Mims, "Remote Work Isn't Just for White-Collar Jobs Anymore," Wall Street Journal, Oct. 2020.

[10] GitLab, "The remote work report by gitlab: The future of work is remote," Mar. 2020.

[11] Y. Xiao and Z. Fan, "10 technology trends to watch in the COVID-19 pandemic," tech. rep., World Economic Forum, Apr. 2020.

[12] G. Stengel, "Working from home opens the door to employing people with disabilities," Forbes, Apr. 2020.

[13] M. Arntz, S. B. Yahmed, and F. Berlingieri, "Working from home and covid-19-the chances and risks for gender gaps," ZEW expert brief, pp. 2009, 2020.

[14] R. Copleand and P. Grant, "Google to keep employees home until summer 2021 amid coronavirus pandemic," Wall Street Journal, July 2020. 
[15] J. Kelly, "Google CEO Sundar Pichai calls for a 'hybrid' work-from-home model," Forbes, Sept. 2020.

[16] R. Sandler, "Amazon extends work-from-home policy until january," Forbes, July 2020.

[17] A. Chamings, "Apple announces remote work until 2021," SFGate, July 2020 .

[18] M. Gurman, "Apple CEO impressed by remote work, sees permanent changes," Sept. 2020.

[19] L. Ioannou, "What the workforce will look like in 2025 as it morphs due to pandemic," Oct. 2020.

[20] M. Koran, "Facebook expects half of employees to work remotely over next five to 10 years," May 2020.

[21] B. van Kralingen, "Reworking work: IBM's post-pandemic workforce strategy," May 2020.

[22] H. Ravet, "After google, facebook, and twitter, intel to allow employees to work from home until june 2021," Aug. 2020.

[23] K. Hogan, "Embracing a flexible workspace," Oct. 2020.

[24] J. Kelly, "Netflix CEO Reed Hastings is not a fan of working from home and wants his employees back at the office " 12 hours after a vaccine is approved'," Forbes, Sept. 2020.

[25] J. Drake, "A three step strategy for who should return to work and when," June 2020.

[26] C. Boll and S. Schüller, "The situation is serious, but not hopeless: Evidence-based considerations on the intracouple division of childcare before, during and after the covid-19 lockdown," tech. rep., SOEPpapers on Multidisciplinary Panel Data Research, 2020.

[27] C. O'Connor, "Gendered division of labor served a purpose. to make progress, don't erase it. replace it.," Dec. 2019.

[28] D. Del Boca, N. Oggero, P. Profeta, and M. Rossi, "Women's and men's work, housework and childcare, before and during covid-19," Review of Economics of the Household, pp. 1-17, 2020.

[29] K. Hank and A. Steinbach, "The virus changed everything, didn't it? couples' division of housework and childcare before and during the corona crisis," Journal of Family Research, 2020.

[30] C. Hupkau and B. Petrongolo, "Work, care and gender during the covid-19 crisis," 2020. 
[31] L. Mangiavacchi, L. Piccoli, and L. Pieroni, "Fathers matter: Intrahousehold responsibilities and children's wellbeing during the COVID-19 lockdown in italy," 2020.

[32] L. Farré, Y. Fawaz, L. González, and J. Graves, "How the covid-19 lockdown affected gender inequality in paid and unpaid work in spain," 2020.

[33] A. C. Morgan, S. F. Way, M. J. D. Hoefer, D. B. Larremore, M. Galesic, and A. Clauset, "The unequal impact of parenthood in academia," Science Advances, vol. 7, no. 9, 2021.

[34] K. R. Myers, W. Y. Tham, Y. Yin, N. Cohodes, J. G. Thursby, M. C. Thursby, P. Schiffer, J. T. Walsh, K. R. Lakhani, and D. Wang, "Unequal effects of the covid-19 pandemic on scientists," Nature human behaviour, vol. 4, no. 9, pp. 880-883, 2020.

[35] M. C. Franco, Â. P. Daneris, T. Mazzetti, H. S. Schuch, M. S. Cenci, and D. Moher, "The impact of COVID-19 on gender gap in dental scientists," 2020 .

[36] R. Rincon and U. Nguyen, "SWE survey report: Impact of COVID-19 on women in engineering and technology," tech. rep., Society of Women Engineers, July 2020. Section: Member News.

[37] A. Arbaje, "Coronavirus and COVID-19: Caregiving for the elderly."

[38] T. Deryugina, O. Shurchkov, and J. E. Stearns, "Covid-19 disruptions disproportionately affect female academics," tech. rep., National Bureau of Economic Research, 2021.

[39] R. J. Erickson, "Why emotion work matters: Sex, gender, and the division of household labor," Journal of Marriage and Family, vol. 67, no. 2, pp. 337-351, 2005. Publisher: [Wiley, National Council on Family Relations].

[40] A. Gezici and O. Ozay, "How race and gender shape covid-19 unemployment probability," SSRN, July 2020.

[41] C. Flaherty, "Women's journal submission rates continue to fall," Inside Higher Ed, Aug. 2020.

[42] E. Dugarova, "Unpaid care work in times of the covid-19 crisis: Gendered impacts, emerging evidence and promising policy responses," 2020.

[43] M.-T. Wang and J. L. Degol, "Gender gap in science, technology, engineering, and mathematics (stem): Current knowledge, implications for practice, policy, and future directions," Educational psychology review, vol. 29, no. 1, pp. 119-140, 2017.

[44] C. Flaherty, "Early journal submission data suggest COVID-19 is tanking women's research productivity," Apr. 2020. 
[45] P. Vincent-Lamarre, C. R. Sugimoto, and V. Larivière, "The decline of women's research production during the coronavirus pandemic," May 2020.

[46] T. Alon, M. Doepke, J. Olmstead-Rumsey, and M. Tertilt, "This time it's different: The role of women's employment in a pandemic recession," tech. rep., National Bureau of Economic Research, 2020.

[47] Catalyst, "The impact of Covid-19 on workplace inclusion: Survey," July 2020.

[48] B. Schulte and H. Swenson, "An unexpected upside to lockdown: men have discovered housework," The Guardian, June 2020.

[49] K. J. Holland, L. M. Cortina, V. J. Magley, A. L. Baker, and F. F. Benya, "Don't let covid-19 disrupt campus climate surveys of sexual harassment," Proceedings of the National Academy of Sciences, vol. 117, no. 40, pp. 24606-24608, 2020.

[50] C. Johnson, "States won't collect LGBTQ data on COVID-19 - and advocates aren't happy," Washington Blade: Gay News, Politics, LGBT Rights, Apr. 2020. Section: Coronavirus.

[51] A. Liptak, "Civil rights law protects gay and transgender workers, supreme court rules," The New York Times, June 2020.

[52] A. Liptak, "Supreme court revives transgender ban for military service," The New York Times, Jan. 2019.

[53] M. Sanger-Katz and N. Weiland, "Trump administration erases transgender civil rights protections in health care," The New York Times, Aug. 2020.

[54] S. James, "Coronavirus economy especially harsh for transgender people," The New York Times, June 2020.

[55] K. Schilt and C. Connell, "Do workplace gender transitions make gender trouble?," Gender, Work $\&$ Organization, vol. 14, no. 6, pp. 596-618, 2007. _eprint: https://onlinelibrary.wiley.com/doi/pdf/10.1111/j.14680432.2007.00373.x.

[56] K. Schilt, "Just one of the guys? how transmen make gender visible at work," Gender and Society, vol. 20, no. 4, pp. 465-490, 2006. Publisher: Sage Publications, Inc.

[57] K. K. Dray, V. R. E. Smith, T. P. Kostecki, I. E. Sabat, and C. R. Thomson, "Moving beyond the gender binary: Examining workplace perceptions of nonbinary and transgender employees," Gender, Work \& Organization, vol. n/a, Apr. 2020. _eprint: https://onlinelibrary.wiley.com/doi/pdf/10.1111/gwao.12455.

[58] S. U. Noble, Algorithms of oppression: How search engines reinforce racism. nyu Press, 2018. 
[59] J. A. Buolamwini, Gender shades: intersectional phenotypic and demographic evaluation of face datasets and gender classifiers. PhD thesis, Massachusetts Institute of Technology, 2017.

[60] R. Abebe, S. Barocas, J. Kleinberg, K. Levy, M. Raghavan, and D. G. Robinson, "Roles for computing in social change," in Proceedings of the 2020 Conference on Fairness, Accountability, and Transparency, pp. 252260, 2020.

[61] C. A. Moss-Racusin, J. F. Dovidio, V. L. Brescoll, M. J. Graham, and J. Handelsman, "Science faculty's subtle gender biases favor male students," Proceedings of the national academy of sciences, vol. 109, no. 41, pp. 16474-16479, 2012.

[62] L. A. Cooper, "COVID-19 racial data transparency."

[63] G. McGraw, "Opinion | How do you fight the Coronavirus without running water?," The New York Times, May 2020.

[64] M. Gogineni, "Zoom launches Zapps to bring third-party apps into video calls," Oct. 2020.

[65] G. J. Borjas and H. Cassidy, "The adverse effect of the covid-19 labor market shock on immigrant employment," tech. rep., National Bureau of Economic Research, 2020.

[66] G. P. Shaw and D. Molnar, "Non-native English language speakers benefit most from the use of lecture capture in medical school," Biochemistry and Molecular Biology Education, vol. 39, no. 6, pp. 416-420, 2011.

[67] V. L. Blake and T. T. Surprenant, "Electronic immigrants in the information age: Public policy considerations," The Information Society, vol. 7, no. 3, pp. 233-244, 1990.

[68] M. Leonardi, J. Bickenbach, T. B. Ustun, N. Kostanjsek, and S. Chatterji, "The definition of disability: what is in a name?," The Lancet, vol. 368, no. 9543, pp. 1219-1221, 2006.

[69] A. Maher and C. Von Hippel, "Individual differences in employee reactions to open-plan offices," Journal of environmental psychology, vol. 25, no. 2, pp. 219-229, 2005.

[70] B. A. Evanoff, J. R. Strickland, A. M. Dale, L. Hayibor, E. Page, J. G. Duncan, T. Kannampallil, and D. L. Gray, "Work-related and personal factors associated with mental well-being during covid-19 response: A survey of health care and other workers," medRxiv, 2020.

[71] P. Choudhury, C. Foroughi, and B. Z. Larson, "Work-from-anywhere: The productivity effects of geographic flexibility," in Academy of Management Proceedings, vol. 2020, p. 21199, Academy of Management Briarcliff Manor, NY 10510, 2020. 
[72] P. Hunter, "Remote working in research: An increasing usage of flexible work arrangements can improve productivity and creativity," EMBO reports, vol. 20, no. 1, p. e47435, 2019.

[73] L. M. Verbrugge, C. Rennert, and J. H. Madans, "The great efficacy of personal and equipment assistance in reducing disability." American journal of public health, vol. 87, no. 3, pp. 384-392, 1997.

[74] V. Romo, "FDA Approves 1st At-Home Coronavirus Test," National Public Radio, Nov. 2020.

[75] C. Hipes, J. Lucas, J. C. Phelan, and R. C. White, "The stigma of mental illness in the labor market," Social Science Research, vol. 56, pp. 16-25, 2016.

[76] S. Kim, "How people's misconceptions of disability lead to toxic microagressions," Forbes, Feb. 2019.

[77] D. Dongarwar, K. K. Yusuf, S. O. Maiyegun, S. Ibrahimi, C. Ikedionwu, and H. M. Salihu, "Covid-19 and neuro-behavioral economics: A conceptual framework to improve physical and mental health among remote workers," International Journal of Maternal and Child Health and AIDS, vol. 9, no. 3, p. $360,2020$.

[78] F. W. Hager, "Links between telecommuting, social support and mental well-being among teleworkers," International Journal of Business and Management, vol. 6, no. 2, 2018.

[79] J. M. Barrero, N. Bloom, and S. J. Davis, "60 million fewer commuting hours per day: How americans use time saved by working from home," University of Chicago, Becker Friedman Institute for Economics Working Paper, no. 2020-132, 2020.

[80] A. Dolot, "The influence of COVID-19 pandemic on the remote work - an employee perspective," E-MENTOR, vol. 1, pp. 35-43, 2020.

[81] L. Bonacini, G. Gallo, and S. Scicchitano, "Working from home and income inequality: risks of a "new normal'with covid-19," Journal of Population Economics, pp. 1-58, 2020. 